\title{
Clinical Impact of Re-irradiation with Carbon-ion Radiotherapy for Lymph Node Recurrence of Gynecological Cancers
}

\author{
SHINTARO SHIBA ${ }^{1,2}$, NORIYUKI OKONOGI $^{1}$, SHINGO KATO $^{3}$, \\ MASARU WAKATSUKI ${ }^{1,4}$, DAIJIRO KOBAYASHI ${ }^{2,5}$, HIROKI KIYOHARA $^{6}$, \\ TATSUYA OHNO ${ }^{2}$, KUMIKO KARASAWA ${ }^{7}$, TAKASHI NAKANO ${ }^{2}$ and TADASHI KAMADA ${ }^{1}$ \\ ${ }^{1}$ Hospital, National Institute of Radiological Sciences, \\ National Institutes for Quantum and Radiological Science and Technology, Chiba, Japan; \\ ${ }^{2}$ Department of Radiation Oncology, Gunma University Graduate School of Medicine, Maebashi, Japan; \\ ${ }^{3}$ Department of Radiation Oncology, Saitama Medical University International Medical Center, Hidaka, Japan; \\ ${ }^{4}$ Department of Radiology, Jichi Medical University, Shimotsuke, Japan; \\ ${ }^{5}$ Cyber Center, Kanto Neurosurgical Hospital, Kumagaya, Japan; \\ ${ }^{6}$ Department of Radiation Oncology, Maebashi Red Cross Hospital, Maebashi, Japan; \\ ${ }^{7}$ Department of Radiation Oncology, Tokyo Women's Medical University, School of Medicine, Tokyo, Japan
}

\begin{abstract}
Background/Aim: To evaluate the safety and efficacy of re-irradiation with carbon-ion radiotherapy $(C$-ion RT) for lymph node recurrence of gynecological cancers after definitive radiotherapy. Patients and Methods: Data regarding patients with unresectable and isolated recurrent lymph node from gynecological cancer after definitive radiotherapy were analyzed. Total dose of C-ion RT was 48-57.6 Gy (RBE) in 12 or 16 fractions. Results: Sixteen patients received reirradiation by $C$-ion $R T$ were analyzed. Median follow-up was 37 months. Median tumor size was $27 \mathrm{~mm}$. None developed Grade 1 or higher acute toxicities and Grade 3 or higher late toxicities. The 3-year overall survival, local control and disease-free survival rates after C-ion RT were $74 \%, 94 \%$ and $55 \%$, respectively. Conclusion: Re-irradiation with C-ion RT for lymph node recurrence of gynecological cancers after definitive radiotherapy can be safe and effective. This result suggested that $C$-ion $R T$ could be a curative treatment option for conventionally difficult-to-cure patients.
\end{abstract}

Gynecological cancers after definitive radiotherapy (RT) often recur. The first choice of treatment for a pelvic

Correspondence to: Prof. Masaru Wakatsuki, Department of Radiology, Jichi Medical University, 3311-1, Yakushiji, Simotsukecity, Tochigi 329-0498, Japan. Tel: +81 285587161, Fax: +81 285444296, e-mail: wakkun100@yahoo.co.jp

Key Words: Carbon-ion radiotherapy, re-irradiation, gynecological cancer, lymph node recurrence. recurrence in the irradiated area has been surgery (1), but some of the patients could not undergo surgery for reasons such as location of the recurrence, being technically unresectable or refusing extirpative surgery. Radiotherapy was considered one of the treatment options for these patients. However, most of these patients need to take into consideration the possibility that normal tissues such as bowel might receive a high cumulative dose. Thus, these patients could not receive curative local treatment, instead selecting chemotherapy or best supportive care (1). Chemotherapy and best supportive care would not be expected to result in long-term survival. Kitagawa et al. reported median survival of stage IVB cervical cancer patients treated with paclitaxel plus cisplatin of 18 months, and that with paclitaxel plus carboplatin of 17 months (2). In addition, previous studies revealed that the response rate of recurrent tumor in the irradiated field for cervical cancer treated with chemotherapy was still approximately $30 \%$, so it was difficult to cure with chemotherapy alone (3-5).

Carbon-ion (C-ion) beams improve the dose localization properties because their Bragg peak results in a distal-tail off and a sharp lateral penumbra. This property of $\mathrm{C}$-ion beams provides a highly conformal dose distribution, and enables the delivery of a high dose to tumors while minimizing normal tissue damage. Moreover, $\mathrm{C}$-ion beams possess a biological advantage due to their high linear energy transfer (LET) in the Bragg peak (6-9). Therefore, even for reirradiation cases, C-ion RT was considered to deliver a sufficient dose to the tumor while normal tissues received a tolerable dose. Until now, there have only been a few reports 
of re-irradiation after definitive RT for lymph node recurrence (10). The current study analyzed re-irradiation with C-ion RT for lymph node recurrence of multiple cases of gynecological cancer after definitive RT. Thus, this retrospective study reported the safety and efficacy of reirradiation with $\mathrm{C}$-ion $\mathrm{RT}$ for lymph node recurrence of gynecological cancers after definitive RT.

\section{Materials and Methods}

Patients. The eligibility criteria of this retrospective study were as follows. 1) The patient had recurrent tumor from gynecological cancer after definitive radiotherapy. 2) There was only one lesion of recurrence within or at the edge of the previously irradiated field. 3) In principal, the distance between tumor and nearest intestinal tract was more than $10 \mathrm{~mm}$. 4) The tumor was unresectable. 5) The patient had no other active malignancy.

Pretreatment evaluation for C-ion RT consisted of an assessment of the patient's history, routine blood cell counts, chemistry profile and chest X-ray, and computed tomography (CT) scans of the pelvis and abdomen were also performed for all patients. Magnetic resonance imaging (MRI) and positron emission tomography (PET) were performed if considered necessary. The treatment protocol for the current study was reviewed and approved by the National Institute of Radiological Sciences Ethics Committee of Human Clinical Research, and all patients signed an informed consent form before the initiation of therapy.

Carbon-ion radiotherapy. Carbon-ion beams were generated using the synchrotron at the National Institute of Radiological Sciences. Tailor-made fixation cushions and thermoplastic shells were used for the immobilization of patients for acquiring treatment-planning CT. After immobilization, respiratory-gated CT was performed. For targeting, the gross tumor volume (GTV) was identified as the obvious tumor by planning CT. The clinical target volume (CTV) was defined as GTV plus $5 \mathrm{~mm}$. Bone, muscle and vessels were excluded from CTV. The planned target volume (PTV) was defined as CTV plus $3 \mathrm{~mm}$. The radiation dose was calculated for the target volume and surrounding normal structures and was expressed in Gy (relative biological effect (RBE)), which was defined as the physical dose multiplied by RBE of C-ion (11). Total dose of C-ion RT was 48-57.6 Gy (RBE) in 12 or 16 fractions. This analysis was not a dose escalation study. The prescribed dose was changed in accordance with the time-line of C-ion RT, tumor size, and histological type. The patients registered between July 2008 and October 2009 were treated with 48 Gy (RBE) in 12 fractions, and those registered since April 2012 were treated with 52.8 Gy (RBE) in 12 fractions. Bulky tumors and radioresistant tumors such as mucinous adenocarcinoma and carcinosarcoma were treated with $57.6 \mathrm{~Gy}(\mathrm{RBE})$ in 12 or 16 fractions. As an exception, one squamous cell carcinoma $24 \mathrm{~mm}$ in size received 57.6 Gy (RBE) in 12 fractions because the dose to the intestinal tract could be reduced by insertion of a spacer. These doses were decided on the basis of other clinical trials and studies at that time (12-17). The dose to intestinal tracts was reduced as much as possible, setting on $20-30 \%$ or less of the prescribed dose.

Patients received C-ion RT once daily, 4 days per week (Tuesday to Friday). At every treatment session, the patient was positioned on the treatment couch with the tailored immobilization devices, and the patient's position was verified by computer-aided, on-line positioning system. Digital orthogonal X-ray images were taken and transferred to the positioning computer. These positioning images were compared with reference images that were digitally reconstructed from $\mathrm{CT}$ scans. If the difference in positioning was $>$ $2 \mathrm{~mm}$, the treatment couch was moved until an acceptable position was attained. Figure 1 shows the typical dose distribution for a patient with common iliac lymph node recurrence.

Assessment of toxicity and efficacy. After completion of C-ion RT, patients were followed up every 1-3 months for 2 years, and every 3-6 months thereafter. Acute toxicity was graded according to the Common Terminology Criteria for Adverse Events, version 4.0 (18), with the highest toxicity within 3 months from the initiation of Cion RT. Late toxicity was graded according to the Radiation Therapy Oncology Group/European Organization for Research and Treatment of Cancer late radiation morbidity scoring scheme (19). Survival was measured from the date of initiation of C-ion RT to the date of death or most recent follow-up. Treatment effects were evaluated in terms of overall survival (OS), local control (LC) and disease-free survival (DFS). Local failure was evaluated as irradiated lymph node recurrence after C-ion RT. The effect of treatment was evaluated on the basis of tumor regrowth or recurrence according to CT, MRI and PET. OS, LC and DFS rates were calculated by Kaplan-Meier method. Log-rank test was used for statistical analyses performed with SPSS software, version 22 (SAS Institute, Tokyo, Japan). Statistical significance was defined as a $p$-value $<0.05$.

\section{Results}

Between July 2008 and October 2016, 16 patients were enrolled in this study. Patient characteristics were summarized in Table I. Median follow-up of all patients was 37 months (range $=3$ 104 months). The data of this study were analyzed in May 2017. Median age at the time of registration for C-ion RT was 57 years (range $=35-79$ years), and median tumor size was $27 \mathrm{~mm}$ (range $=14-80 \mathrm{~mm}$ ). Initial treatment consisted of surgery in 11 patients, RT alone in 1 patient, and concurrent chemoradiotherapy in 4 patients. All patients had received RT as part of the initial treatment or treatment of postoperative recurrence. Three patients received surgical spacer placement by open surgery to keep intestinal tracts apart from the tumor, as the distance between tumor and nearest intestinal tracts was not sufficient. Median distance between tumor and the nearest intestinal tract was $12 \mathrm{~mm}$ (range $=10-27 \mathrm{~mm}$ ) except for the 3 patients with inserted spacer. Total dose of C-ion RT was $48 \mathrm{~Gy}$ (RBE) in 12 fractions for 4 patients, 52.8 Gy (RBE) in 12 fractions for 8 patients, 57.6 Gy (RBE) in 12 fractions for 3 patients, and $57.6 \mathrm{~Gy}$ (RBE) in 16 fractions for 1 patient. The median D2cc of the intestinal tract was 7.3 Gy (RBE) (range=1.2-47.4 Gy (RBE)). There were some cases with evaluated D2cc of the intestinal tract. Their tumors were recurrences from the edge of the previously irradiated field. The intestinal tracts near the tumor had not been exposed to the full dose of prior radiotherapy. Additionally, their follow-up duration was more than 60 months, and none of these 4 cases developed 

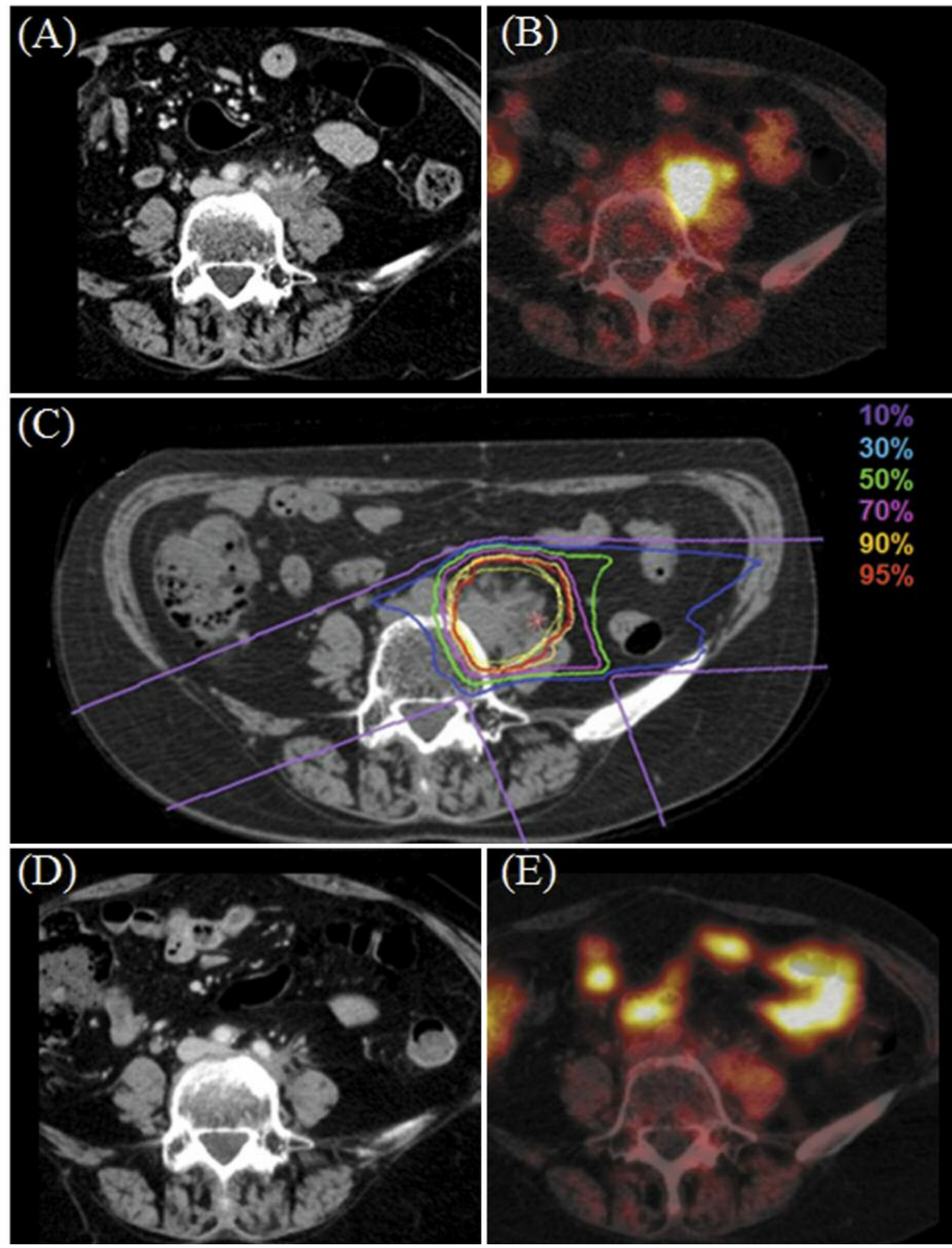

Figure 1. Common iliac lymph node recurrence with cervical cancer. (A) Enhanced axial CT image shows enlarged lymph node in left iliac area. (B) Axial FDG-PET image shows abnormal FDG uptake corresponding to enlarged common iliac lymph node. (C) Dose distribution of C-ion RT for common iliac lymph node recurrence. Isodose curves of C-ion RT are superimposed on an axial CT image for the total irradiation plan. Highlighted are 95\% (red), 90\% (orange), 70\% (pink), 50\% (green), 30\% (blue), 10\% (purple) isodose curves (100\% was 52.8 Gy (RBE)). (D) Enhanced axial CT image 18 months after C-ion RT. (E) Axial FDG-PET image 12 months after C-ion RT shows no abnormal FDG uptake. 


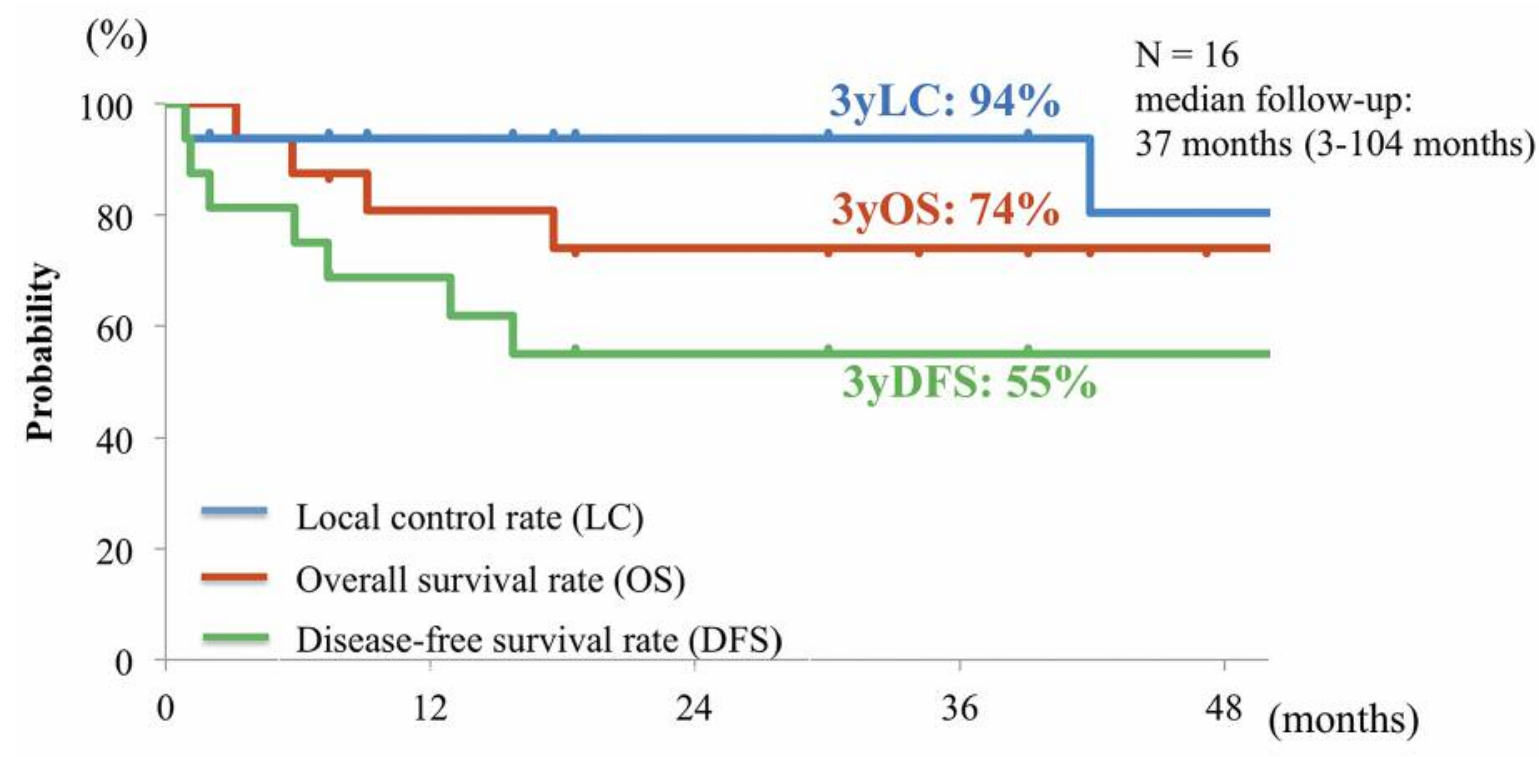

Months after treatment

Figure 2. Overall survival, local control, and disease-free survival curves. Overall survival (red line), local control (blue line), and disease-free survival (green line) of all patients treated with C-ion RT are shown.

severe toxicities. All patients completed the treatment and no acute toxicities were observed. All observed late toxicities are listed in Table II. No patients developed Grade 3 or higher late toxicities. The 3-year OS, LC and DFS rates and 95\% confidence interval (CI) after C-ion RT were $74 \%$ (95\% CI, 48$90 \%), 94 \%(95 \% \mathrm{CI}, 66-99 \%)$ and $55 \%$ (95\% CI, 31-77\%), respectively (Figure 2). Two patients had local recurrence, and 7 patients had distant metastases (Table I).

\section{Discussion}

The current study showed no severe toxicities and good local control with $\mathrm{C}$-ion $\mathrm{RT}$ for lymph node recurrence of gynecological cancers after definitive RT. Thus, C-ion RT appears to be a safe and effective treatment, and could be expected to represent a curative treatment option for these patients.

Recurring tumors of the pelvic or para-aortic lymph node area within or at the edge of a previously irradiated field were often in close proximity to the intestinal tract. Severe toxicities could result if the initial and second radiation fields were overlapped on normal tissues such as the bowel, as the cumulative dose surpasses the tolerance dose. Park et al. reported stereotactic body RT (SBRT) for recurrent or oligometastatic cervical cancer (20). They reported that 68 of 100 sites were re-irradiation cases, and that the 2-year local progression-free survival rate was $60.2 \%$ in the re-irradiation group. Re-irradiation was related to inferior local control, but the dose of SBRT for the re-irradiation group was far less than the dose for other groups. As for toxicities, 5 patients developed Grade 3 or higher. It was considered that normal tissues were exposed to higher than tolerance doses. This result suggested that, in some re-irradiation of recurrent or oligometastatic tumor cases, SBRT with X-rays could not deliver a curative dose.

In terms of dose constraints for initial RT, in the 50-Gy irradiated small bowel, late toxicities of obstruction or perforation rates were reported to be $2 \%$ to $9 \%$ (21). Furthermore, to reduce Grade 3 or higher late rectal toxicity, rectal V50, V60, V65, V70 and V75 were limited to less than $50 \%, 35 \%, 25 \%, 20 \%$ and $15 \%$, respectively (22). Although standard-dose constraints for re-irradiation with C-ion RT had not been established, it was considered that the cumulative dose should not exceed the dose constraint of initial RT. In cases of tumor and intestinal tract being in close proximity, staying within the dose constraint was difficult, and therefore such patients were treated with chemotherapy or best supportive care. In the current study, even though the tumor was near the intestinal tract, all patients completed the treatment course safely, and there were no acute toxicities or Grade 3 or higher late toxicities by re-irradiation with $\mathrm{C}$-ion RT. Thus, C-ion RT could be considered a safe and effective treatment for cases with re-irradiation of conventionally difficult curative RT because of overlapped initial and second radiation fields.

Recently, the concept of oligometastases was proposed. It was shown that a few distant metastases, as the concept of oligometastases, given adequate local treatment, resulted 
Table I. Patient characteristics and clinical outcomes.

\begin{tabular}{|c|c|c|c|c|c|c|c|c|}
\hline Case & $\begin{array}{c}\text { Primary site, } \\
\text { Stage }\end{array}$ & Histology & $\begin{array}{c}\text { Initial } \\
\text { treatment }\end{array}$ & $\begin{array}{l}\text { Dose of } \\
\text { prior RT }\end{array}$ & $\begin{array}{c}\text { Duration of } \\
\text { prior RT to } \\
\text { C-ion RT } \\
\text { (months) }\end{array}$ & $\begin{array}{l}\text { Tumor } \\
\text { size } \\
(\mathrm{mm})\end{array}$ & $\begin{array}{c}\text { Dose of } \\
\text { C-ion RT }\end{array}$ & Recurrence \\
\hline 1 & $\begin{array}{l}\text { Cervical cancer, } \\
\text { T2bN1M0 }\end{array}$ & $\begin{array}{l}\text { Squamous cell } \\
\text { carcinoma }\end{array}$ & CCRT & $50 \mathrm{~Gy} / 25 \mathrm{fr}$. & 26 & 33 & 48 Gy (RBE)/12 fr. & NER \\
\hline 2 & $\begin{array}{c}\text { Cervical cancer, } \\
\text { T2aN0M0 }\end{array}$ & $\begin{array}{l}\text { Squamous cell } \\
\text { carcinoma }\end{array}$ & RT alone & $50 \mathrm{~Gy} / 25 \mathrm{fr}$. & 25 & 28 & 48 Gy $(\mathrm{RBE}) / 12$ fr. & NER \\
\hline 3 & $\begin{array}{c}\text { Endometrial cancer, } \\
\text { T1N0M0 }\end{array}$ & $\begin{array}{c}\text { Endometrioid } \\
\text { adenocarcinoma }\end{array}$ & Surgery & $50 \mathrm{~Gy} / 25 \mathrm{fr}$ & 68 & 25 & 48 Gy (RBE)/12 fr. & NER \\
\hline 4 & $\begin{array}{l}\text { Cervical cancer, } \\
\text { T4NOM0 }\end{array}$ & $\begin{array}{l}\text { Squamous cell } \\
\text { carcinoma }\end{array}$ & CCRT & $50 \mathrm{~Gy} / 25 \mathrm{fr}$. & 26 & 14 & $48 \mathrm{~Gy}(\mathrm{RBE}) / 12 \mathrm{fr}$. & LN metastasis \\
\hline 5 & $\begin{array}{l}\text { Cervical cancer, } \\
\text { T1b1N0M0 }\end{array}$ & $\begin{array}{l}\text { Squamous cell } \\
\text { carcinoma }\end{array}$ & Surgery & $66 \mathrm{~Gy} / 33 \mathrm{fr}$. & 11 & 33 & $52.8 \mathrm{~Gy}(\mathrm{RBE}) / 12 \mathrm{fr}$. & NER \\
\hline 6 & $\begin{array}{c}\text { Endometrial cancer, } \\
\text { T3aN0M0 }\end{array}$ & Carcinosarcoma & Surgery & $60 \mathrm{~Gy} / 30 \mathrm{fr}$. & 12 & 20 & $57.6 \mathrm{~Gy}(\mathrm{RBE}) / 12 \mathrm{fr}$. & LN metastasis \\
\hline 7 & $\begin{array}{l}\text { Cervical cancer, } \\
\text { T3bN1M0 }\end{array}$ & $\begin{array}{l}\text { Squamous cell } \\
\text { carcinoma }\end{array}$ & Surgery & $50 \mathrm{~Gy} / 25 \mathrm{fr}$. & 17 & 15 & $52.8 \mathrm{~Gy}(\mathrm{RBE}) / 12 \mathrm{fr}$. & $\begin{array}{l}\text { Local recurrence, } \mathrm{LN} \\
\text { and Lung metastases }\end{array}$ \\
\hline 8 & $\begin{array}{l}\text { Cervical cancer, } \\
\text { T2bN1M0 }\end{array}$ & $\begin{array}{l}\text { Squamous cell } \\
\text { carcinoma }\end{array}$ & CCRT & $50.6 \mathrm{~Gy} / 27 \mathrm{fr}$. & 33 & 24 & 57.6 Gy $(\mathrm{RBE}) / 12 \mathrm{fr}$. & LN metastasis \\
\hline 9 & $\begin{array}{c}\text { Endometrial cancer, } \\
\text { T3bN1M0 }\end{array}$ & $\begin{array}{l}\text { Endometrioid } \\
\text { adenocarcinoma }\end{array}$ & Surgery & $50 \mathrm{~Gy} / 25 \mathrm{fr}$. & 20 & 80 & $57.6 \mathrm{~Gy}(\mathrm{RBE}) / 16 \mathrm{fr}$. & Local recurrence \\
\hline 10 & $\begin{array}{l}\text { Cervical cancer, } \\
\text { T2aN0M0 }\end{array}$ & $\begin{array}{l}\text { Squamous cell } \\
\text { carcinoma }\end{array}$ & CCRT & $46 \mathrm{~Gy} / 23 \mathrm{fr}$. & 77 & 30 & $52.8 \mathrm{~Gy}(\mathrm{RBE}) / 12 \mathrm{fr}$. & NER \\
\hline 11 & $\begin{array}{c}\text { Ovarian cancer, } \\
\text { T1bNOM0 }\end{array}$ & $\begin{array}{c}\text { Serous } \\
\text { adenocarcinoma }\end{array}$ & Surgery & $56 \mathrm{~Gy} / 28 \mathrm{fr}$. & 40 & 18 & $52.8 \mathrm{~Gy}(\mathrm{RBE}) / 12 \mathrm{fr}$. & Lung metastasis \\
\hline 12 & $\begin{array}{c}\text { Endometrial cancer, } \\
\text { T3aN0M0 }\end{array}$ & $\begin{array}{c}\text { Endometrioid } \\
\text { adenocarcinoma }\end{array}$ & Surgery & $50 \mathrm{~Gy} / 25 \mathrm{fr}$. & 130 & 22 & $52.8 \mathrm{~Gy}(\mathrm{RBE}) / 12 \mathrm{fr}$. & NER \\
\hline 13 & $\begin{array}{c}\text { Endometrial cancer, } \\
\text { T1bN0M0 }\end{array}$ & $\begin{array}{l}\text { Small cell } \\
\text { carcinoma }\end{array}$ & Surgery & $54 \mathrm{~Gy} / 27 \mathrm{fr}$. & 17 & 75 & $52.8 \mathrm{~Gy}(\mathrm{RBE}) / 12 \mathrm{fr}$. & Lung metastasis \\
\hline 14 & $\begin{array}{l}\text { Cervical cancer, } \\
\text { T1bN0M0 }\end{array}$ & $\begin{array}{c}\text { Mucinous } \\
\text { adenocarcinoma }\end{array}$ & Surgery & $50.4 \mathrm{~Gy} / 28 \mathrm{fr}$. & 21 & 38 & $57.6 \mathrm{~Gy}(\mathrm{RBE}) / 12 \mathrm{fr}$. & NER \\
\hline 15 & $\begin{array}{c}\text { Endometrial cancer, } \\
\text { T1bN0M0 }\end{array}$ & $\begin{array}{l}\text { Endometrioid } \\
\text { adenocarcinoma }\end{array}$ & Surgery & $58.6 \mathrm{~Gy} / 32 \mathrm{fr}$. & 29 & 42 & $52.8 \mathrm{~Gy}(\mathrm{RBE}) / 12 \mathrm{fr}$. & Liver metastasis \\
\hline 16 & $\begin{array}{c}\text { Cervical cancer, } \\
\text { T1bN1M0 }\end{array}$ & $\begin{array}{l}\text { Squamous cell } \\
\text { carcinoma }\end{array}$ & Surgery & $50 \mathrm{~Gy} / 25 \mathrm{fr}$. & 64 & 20 & $52.8 \mathrm{~Gy}(\mathrm{RBE}) / 12 \mathrm{fr}$. & NER \\
\hline
\end{tabular}

CCRT, Concurrent chemoradiotherapy; C-ion RT, carbon-ion radiotherapy; fr., fractions; LN, lymph node; NER, no evidence of recurrence; RT, radiotherapy.

in longer survival. Niibe et al. reported the clinical outcomes of initial RT for para-aortic lymph node recurrence of uterine cervical cancer as single-site tumor progression, and they had 3-year and 5-year OS rates of $50 \%$ and $31 \%$, respectively (23). They suggested that initial RT for isolated para-aortic recurrence in uterine cervical cancer could achieve longer survival. However, there was no evidence that re-irradiation for isolated lymph node recurrence achieves longer survival. In the current study, with a limited the number of 16 patients, the 3-year OS and LC rates were $74 \%$ and $94 \%$. This result was comparable or better than that of initial RT for oligometastases (24-26). The current study suggested that better local control of reirradiation with C-ion RT for isolated lymph node recurrence achieved longer survival.
Table II. Late toxicities by RTOG/EORTC scoring scheme $(N=16)$.

\begin{tabular}{lccccc}
\hline Organs involved & G0 & G1 & G2 & G3 & G4 \\
\hline Gastrointestinal tract & 14 & 2 & 0 & 0 & 0 \\
Urinary tract & 15 & 1 & 0 & 0 & 0 \\
Leg edema & 15 & 0 & 1 & 0 & 0 \\
Lower extremity nerve & 14 & 2 & 0 & 0 & 0 \\
\hline
\end{tabular}

RTOG/EORTC, Radiation Therapy Oncology Group/European Organization for Research and Treatment of Cancer.

Several studies reported X-ray-induced radioresistance in various cancer cell lines (27-31). It was considered that recurrent tumors after RT possibly developed due to X-ray- 
induced resistance to RT. C-ion RT was expected to achieve a better therapeutic effect than $\mathrm{X}$-rays against radioresistant tumors, as $\mathrm{C}$-ion beams possess a biological advantage due to their higher LET, which is considered to have contributed to a better LC $(32,33)$.

The distance between tumor and nearest intestinal tract was one of the limitations of the current study. Kato et al. and Matsushita et al. reported that a dose over 60 Gy (RBE) had a high risk of intestinal perforation $(12,34)$. The prescribed dose in the current study was 48-57.6 Gy (RBE). If the intestinal tract would be exposed to the full dose of Cion RT, this dose added to that of prior RT would exceed the tolerable dose for the intestinal tract. Thus, an eligibility criterion of the current study was a distance between tumor and nearest intestinal tract of more than $10 \mathrm{~mm}$. This distance setting of $10 \mathrm{~mm}$ was based on the properties of Cion beams reported by Kanai et al. (7) and Sihver et al. (35). Kanai et al. measured the size of the penumbra and reported that the distance from the position of $80 \%$ dose level to that of $20 \%$ level was around $2-3 \mathrm{~mm}$ in a water phantom in 60 $\mathrm{mm}$ SOBP of $290 \mathrm{MeV} / \mathrm{u} \mathrm{C}$-ion beams. Sihver et al. measured the dose as a function of depth, reporting that the fragment tail attenuated to about $10 \%$ of the Bragg peak 2 $\mathrm{mm}$ on the distal side of the Bragg peak in a water phantom in a monoenergetic primary beam of $270 \mathrm{MeV} / \mathrm{u} \mathrm{C}$-ion. As a result, the median D2cc of the intestinal tract was $7.3 \mathrm{~Gy}$ (RBE), and there were no severe toxicities within the followup duration. Hence, the safety of the present study was confirmed by DVH parameter when the distance between tumor and nearest intestinal tract was set to $10 \mathrm{~mm}$.

Recently, a gore-tex patch was surgically placed as spacer to cover the distance between intestinal tract and tumor. Fukumoto et al. reported the clinical benefit of surgical spacer placement for advanced abdominal leiomyosarcoma treated with particle beam therapy (35). In the case of re-irradiation and/or after surgery, it is sometimes difficult to place a spacer because of wide intestinal adhesion. However, if patients could receive surgical spacer placement, it would be possible to create a sufficient distance between intestinal tracts and tumor. This means that a sufficient dose of C-ion RT could be delivered to the tumor without causing severe toxicities. In this way, although the distance between the tumor and the nearest intestinal tract is close, the patient might become treatable with C-ion RT.

In conclusion, re-irradiation with $\mathrm{C}$-ion RT could meet expectations as a curative treatment option for conventionally difficult-to-cure patients. Although re-irradiation with $\mathrm{C}$-ion RT for LN recurrence of gynecological cancers after definitive RT showed favorable results, the present study has several limitations, including its retrospective nature with the small number of patients analyzed, as well as the short follow-up period. Further research is required to identify the long-term safety and efficacy for a larger number of patients.

\section{Conflicts of Interest}

The Authors have no conflicts of interest to declare.

\section{Acknowledgements}

The Authors would like to thank all patients who were involved in this study and our colleagues at the National Institute of Radiological Sciences. This work was supported by the Research Project with Heavy Ions at the National Institute of Radiological Sciences, Grants-in-Aid from the Ministry of Education, Culture, Sports, Science, and Technology of Japan for programs for Leading Graduate Schools, Cultivating Global Leaders in Heavy Ion Therapeutics and Engineering.

\section{References}

1 Koh W-J, Greer BE, Abu-Rustum NR, Apte SM, Campos SM, Cho $\mathrm{KR}$, Chu C, Cohn D, Crispens MA and Dorigo O: Cervical cancer, version 2.2015. J Natl Compr Canc Netw 13(4): 395-404, 2015.

2 Kitagawa R, Katsumata N, Shibata T, Kamura T, Kasamatsu T, Nakanishi T, Nishimura S, Ushijima K, Takano M, Satoh T and Yoshikawa H: Paclitaxel Plus Carboplatin Versus Paclitaxel Plus Cisplatin in Metastatic or Recurrent Cervical Cancer: The OpenLabel Randomized Phase III Trial JCOG0505. J Clin Oncol 33(19): 2129-2135, 2015.

3 Benjapibal M, Thirapakawong C, Leelaphatanadit C, Therasakvichya S and Inthasorn P: A pilot phase II study of capecitabine plus cisplatin in the treatment of recurrent carcinoma of the uterine cervix. Oncology 72(1-2): 33-38, 2007.

4 Kosmas C, Mylonakis N, Tsakonas G, Vorgias G, Karvounis N, Tsavaris N, Daladimos T, Kalinoglou N, Malamos N, Akrivos T and Karabelis A: Evaluation of the paclitaxel-ifosfamidecisplatin (TIP) combination in relapsed and/or metastatic cervical cancer. Br J Cancer 101(7): 1059-1065, 2009.

5 Pectasides D, Fountzilas G, Papaxoinis G, Pectasides E, Xiros N, Sykiotis C, Koumarianou A, Psyrri A, Panayiotides J and Economopoulos T: Carboplatin and paclitaxel in metastatic or recurrent cervical cancer. Int J Gynecol Cancer 19(4): 777-781, 2009.

6 Ando K, Koike S, Nojima K, Chen YJ, Ohira C, Ando S, Kobayashi N, Ohbuchi T, Shimizu W and Kanai T: Mouse skin reactions following fractionated irradiation with carbon ions. Int J Radiat Biol 74(1): 129-138, 1998.

7 Kanai T, Endo M, Minohara S, Miyahara N, Koyama-ito H, Tomura H, Matsufuji N, Futami Y, Fukumura A, Hiraoka T, Furusawa Y, Ando K, Suzuki M, Soga F and Kawachi K: Biophysical characteristics of HIMAC clinical irradiation system for heavy-ion radiation therapy. Int J Radiat Oncol Biol Phys 44(1): 201-210, 1999.

8 Shiba S, Wakatsuki M, Kato S, Ohno T, Okonogi N, Karasawa K, Kiyohara H, Tsujii H, Nakano T, Kamada T and Shozu M; The Working Group of the Gynecological Tumor: Carbon-ion radiotherapy for locally advanced cervical cancer with bladder invasion. J Radiat Res 57(6): 684-690, 2016.

9 Tsujii $\mathrm{H}$ and Kamada T: A review of update clinical results of carbon ion radiotherapy. Jpn J Clin Oncol 42(8): 670-685, 2012.

10 Tamaki T, Ohno T, Kiyohara H, Noda SE, Ohkubo Y, Ando K, Wakatsuki M, Kato S, Kamada T and Nakano T: Carbon-ion radiotherapy for marginal lymph node recurrences of cervical 
cancer after definitive radiotherapy: a case report. Radiation oncology (London, England) 8: 79, 2013.

11 Inaniwa T, Kanematsu N, Matsufuji N, Kanai T, Shirai T, Noda K, Tsuji H, Kamada T and Tsujii H: Reformulation of a clinicaldose system for carbon-ion radiotherapy treatment planning at the National Institute of Radiological Sciences, Japan. Phys Med Biol 60(8): 3271-3286, 2015.

12 Kato S, Ohno T, Tsujii H, Nakano T, Mizoe JE, Kamada T, Miyamoto $T$, Tsuji $H$, Kato $H$, Yamada $S$, Kandatsu $S$, Yoshikawa K, Ezawa H and Suzuki M; Working Group of the Gynecological Tumor: Dose escalation study of carbon ion radiotherapy for locally advanced carcinoma of the uterine cervix. Int J Radiat Oncol Biol Phys 65(2): 388-397, 2006.

13 Nakano T, Suzuki M, Abe A, Suzuki Y, Morita S, Mizoe J, Sato S, Miyamoto T, Kamada T, Kato H and Tsujii H: The phase I/II clinical study of carbon ion therapy for cancer of the uterine cervix. Cancer J Sci Am 5(6): 362-369, 1999.

14 Tsujii H, Kamada T, Shirai T, Noda K, Tsuji H and Karasawa K: Carbon-ion radiotherapy. Carbon-Ion Radiotherapy Springer, 2014.

15 Wakatsuki M, Kato S, Kiyohara H, Ohno T, Karasawa K, Tamaki T, Ando K, Tsujii H, Nakano T, Kamada T and Shozu M; Working Group of the Gynecological Tumor: Clinical Trial of Prophylactic Extended-Field Carbon-Ion Radiotherapy for Locally Advanced Uterine Cervical Cancer (Protocol 0508) PLoS One 10(5): e0127587, 2015.

16 Wakatsuki M, Kato S, Ohno T, Karasawa K, Ando K, Kiyohara H, Tsujii H, Nakano T, Kamada T and Shozu M; Working Group of the Gynecological Tumor: Dose-escalation study of carbon ion radiotherapy for locally advanced squamous cell carcinoma of the uterine cervix (9902). Gynecol Oncol 132(1): 87-92, 2014.

17 Wakatsuki M, Kato S, Ohno T, Karasawa K, Kiyohara H, Tamaki T, Ando K, Tsujii H, Nakano T, Kamada T and Shozu M; Working Group of the Gynecological Tumor: Clinical outcomes of carbon ion radiotherapy for locally advanced adenocarcinoma of the uterine cervix in phase $1 / 2$ clinical trial (protocol 9704). Cancer 120(11): 1663-1669, 2014.

18 Health UDo and Services H: National Cancer Institute: Common Terminology Criteria for Adverse Events (CTCAE), Version 4.0. US Department of Health and Human Services National Institutes of Health National Cancer Institute 2009.

19 Cox JD, Stetz J and Pajak TF: Toxicity criteria of the Radiation Therapy Oncology Group (RTOG) and the European Organization for Research and Treatment of Cancer (EORTC). Int J Radiat Oncol Biol Phys 31(5): 1341-1346, 1995.

20 Park HJ, Chang AR, Seo Y, Cho CK, Jang WI, Kim MS and Choi C: Stereotactic Body Radiotherapy for Recurrent or Oligometastatic Uterine Cervix Cancer: A Cooperative Study of the Korean Radiation Oncology Group (KROG 14-11). Anticancer Res 35(9): 5103-5110, 2015.

21 Kavanagh BD, Pan CC, Dawson LA, Das SK, Li XA, Ten Haken RK and Miften M: Radiation dose-volume effects in the stomach and small bowel. Int J Radiat Oncol Biol Phys 76(Suppl 3): S101-107, 2010.

22 Halperin EC, Brady LW, Wazer DE and Perez CA: Perez \& Brady's principles and practice of radiation oncology: Lippincott Williams \& Wilkins; 2013.

23 Niibe Y, Kenjo M, Kazumoto T, Michimoto K, Takayama M, Yamauchi C, Kataoka M, Suzuki K, Ii N, Uno T, Takanaka T, Higuchi K, Yamazaki H, Tokumaru S, Oguchi M and Hayakawa $\mathrm{K}$; Japanease Isolated Para-Aortic Lymph Node Recurrence of
Uterine Cervical Carcinoma Study Group: Multi-institutional study of radiation therapy for isolated para-aortic lymph node recurrence in uterine cervical carcinoma: 84 subjects of a population of more than 5,000. Int J Radiat Oncol Biol Phys 66(5): 1366-1369, 2006.

24 Deodato F, Macchia G, Grimaldi L, Ferrandina G, Lorusso D, Salutari V, Cilla S, Valentini V, Cellini N, Piermattei A, Scambia $\mathrm{G}$ and Morganti AG: Stereotactic radiotherapy in recurrent gynecological cancer: a case series. Oncology reports 22(2): 415-419, 2009.

25 Dewas S, Bibault JE, Mirabel X, Nickers P, Castelain B, Lacornerie T, Jarraya $\mathrm{H}$ and Lartigau E: Robotic image-guided reirradiation of lateral pelvic recurrences: preliminary results. Radiation Oncol 6: 77, 2011.

26 Niibe Y, Yamashita H, Sekiguchi K, Takahashi W, Shiraishi K, Okuma K, Terahara A, Kawamori J and Nakagawa K: Stereotactic body radiotherapy results for pulmonary oligometastases: A two-institution collaborative investigation. Anticancer Res 35(9): 4903-4908, 2015.

27 Kuwahara Y, Li L, Baba T, Nakagawa H, Shimura T, Yamamoto Y, Ohkubo Y and Fukumoto M: Clinically relevant radioresistant cells efficiently repair DNA double-strand breaks induced by Xrays. Cancer science 100(4): 747-752, 2009.

28 Lynam-Lennon N, Reynolds JV, Pidgeon GP, Lysaght J, Marignol L and Maher SG: Alterations in DNA repair efficiency are involved in the radioresistance of esophageal adenocarcinoma. Radiat Res 174(6): 703-711, 2010.

29 Pearce AG, Segura TM, Rintala AC, Rintala-Maki ND, Lee H: The generation and characterization of a radiation-resistant model system to study radioresistance in human breast cancer cells. Radiat Res 156(6): 739-750, 2001.

30 Russell J, Wheldon TE and Stanton P: A radioresistant variant derived from a human neuroblastoma cell line is less prone to radiation-induced apoptosis. Cancer Res 55(21): 4915-4921, 1995.

31 Shimura T, Kakuda S, Ochiai Y, Nakagawa H, Kuwahara Y, Takai Y, Kobayashi J, Komatsu K and Fukumoto M: Acquired radioresistance of human tumor cells by DNA-PK/AKT/ GSK3beta-mediated cyclin D1 overexpression. Oncogene 29(34): 4826-4837, 2010.

32 Weichselbaum RR, Dahlberg W, Beckett M, Karrison T, Miller D, Clark J, Ervin TJ: Radiation-resistant and repair-proficient human tumor cells may be associated with radiotherapy failure in head- and neck-cancer patients. Proc Natl Acad Sci USA 83(8): 2684-2688, 1986.

33 Wozny AS, Alphonse G, Battiston-Montagne P, Simonet S, Poncet D, Testa E, Guy JB, Rancoule C, Magne N, Beuve M and Rodriguez-Lafrasse $\mathrm{C}$ : Influence of dose rate on the cellular response to low- and high-LET radiations. Front Oncol 6: 58, 2016.

34 Matsushita K, Ochiai T, Shimada H, Kato S, Ohno T, Nikaido T, Yamada S, Okazumi S, Matsubara H, Takayama W, Ishikura $\mathrm{H}$ and Tsujii $\mathrm{H}$ : The effects of carbon ion irradiation revealed by excised perforated intestines as a late morbidity for uterine cancer treatment. Surg Today 36(8): 692-700, 2006.

35 Fukumoto T, Komatsu S, Hori Y, Murakami M, Hishikawa Y and $\mathrm{Ku} \mathrm{Y}$ : Particle beam radiotherapy with a surgical spacer placement for advanced abdominal leiomyosarcoma results in a significant clinical benefit. J Surg Oncol 101(1): 97-99, 2010.

Received July 18, 2017

Revised August 3, 2017 Accepted August 6, 2017 